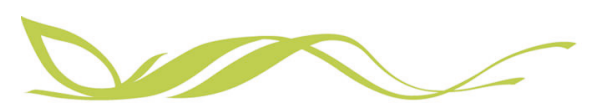

\title{
An integrated approach to quantifying uncertainties in the remaining carbon budget
}

H. Damon Matthews (1) 1,10凶 , Katarzyna B. Tokarska (1) ${ }^{2,10 凶}{ }^{\text {, Joeri Rogelj }}{ }^{3,4}$, Christopher J. Smith (1) ${ }^{5}$, Andrew H. MacDougall ${ }^{6}$, Karsten Haustein (10) ${ }^{7}$, Nadine Mengis (1) ${ }^{8,9}$, Sebastian Sippel (1) ${ }^{2}$, Piers M. Forster ${ }^{5} \&$ Reto Knutti iD ${ }^{2}$

The remaining carbon budget quantifies the future $\mathrm{CO}_{2}$ emissions to limit global warming below a desired level. Carbon budgets are subject to uncertainty in the Transient Climate Response to Cumulative $\mathrm{CO}_{2}$ Emissions (TCRE), as well as to non- $\mathrm{CO}_{2}$ climate influences. Here we estimate the TCRE using observational constraints, and integrate the geophysical and socioeconomic uncertainties affecting the distribution of the remaining carbon budget. We estimate a median TCRE of $0.44{ }^{\circ} \mathrm{C}$ and $5-95 \%$ range of $0.32-0.62{ }^{\circ} \mathrm{C}$ per $1000 \mathrm{GtCO}_{2}$ emitted. Considering only geophysical uncertainties, our median estimate of the $1.5^{\circ} \mathrm{C}$ remaining carbon budget is $440 \mathrm{GtCO}_{2}$ from 2020 onwards, with a range of 230-670 $\mathrm{GtCO}_{2}$, (for a $67-33 \%$ chance of not exceeding the target). Additional socioeconomic uncertainty related to human decisions regarding future non- $\mathrm{CO}_{2}$ emissions scenarios can further shift the median $1.5^{\circ} \mathrm{C}$ remaining carbon budget by $\pm 170 \mathrm{GtCO}_{2}$.

\footnotetext{
${ }^{1}$ Concordia University, Montréal, Canada. ${ }^{2}$ Institute for Atmospheric and Climate Science, ETH Zurich, Zurich, Switzerland. ${ }^{3}$ Grantham Institute, Imperial College London, London, UK. ${ }^{4}$ International Institute for Applied Systems Analysis (IIASA), Laxenburg, Austria. ${ }^{5}$ Priestley International Centre for Climate, University of Leeds, Leeds LS2 9JT, UK. ${ }^{6}$ St. Francis Xavier University, Antigonish, NS, Canada. ${ }^{7}$ Environmental Change Institute, University of Oxford, Oxford, UK. ${ }^{8}$ GEOMAR, Helmholtz Centre for Ocean Research, Kiel, Germany. ${ }^{9}$ Simon Fraser University, Burnaby, BC, Canada. ${ }^{10}$ These authors contributed equally: H. Damon Matthews, Katarzyna B. Tokarska. ${ }_{\text {email: damon.matthews@concordia.ca; kasia.tokarska@env.ethz.ch }}$
} 
$\mathrm{R}$ emaining carbon budgets (RCBs) represent the future cumulative $\mathrm{CO}_{2}$ emissions that would be consistent with keeping global warming to a specified level, such as those mentioned in the Paris Agreement ${ }^{1-4}$, and play an important role in framing the objectives of national and international climate policy. Despite being conceptually simple, RCBs have been defined and estimated in various ways and with many different underlying assumptions, resulting in a wide range of "best estimates" across different studies ${ }^{2}$. Moreover, most of these estimates of remaining budgets account for only a subset of the relevant uncertain processes and often omit the contribution of key uncertain processes (such as permafrost thaw or future scenario uncertainty, among others) $)^{1,2,5-13}$. Given the relevance of carbon budgets to inform climate policy discussions and decisions $^{14}$, it is essential that the key uncertainties associated with the RCB are not only understood but also quantified and integrated into its main estimate.

The IPCC Special Report on Global Warming of $1.5^{\circ} \mathrm{C}$ (hereafter SR1.5; ref. ${ }^{1}$ ) is a prominent recent assessment of the RCB. SR1.5 used a new approach of a segmented framework ${ }^{2}$ that allows for calculating the RCB directly from an estimate of TCRE ${ }^{15-17}$ (informed by both models and observational constraints), an estimate of the anthropogenic warming to date, and information on the temperature response to the future evolution of non- $\mathrm{CO}_{2}$ emissions (generated by running reduced complexity climate model emulators, such as FaIR ${ }^{18,19}$ or MAGICC ${ }^{20}$ ). SR1.5 assessed other sources of uncertainties of the RCB, such as those arising from historical temperature uncertainty, recent $\mathrm{CO}_{2}$ emissions uncertainty, non- $\mathrm{CO}_{2}$ forcing and response, non- $\mathrm{CO}_{2}$ scenario variation, uncertainty in the shape of the TCRE distribution, and consideration of under-represented Earth system feedbacks (ref. ${ }^{1}$; Table 2.2 therein). However, these uncertainties were not incorporated into a single distribution of the RCB, but were rather assessed individually as additional, uncertain factors. The SR1.5 budget assessment reflects the best available information at the time, and highlights a key knowledge gap related to how the distribution of the RCB is affected by uncertainties arising from both geophysical and socioeconomic processes ${ }^{1,2}$. While the segmented framework ${ }^{2}$ used in SR1.5 allows for the assessment of different factors contributing to the RCB estimates, it remains unclear how uncertainties in each of these individual factors affect the overall distribution of the remaining budget estimate.

Here we quantify the distribution of TCRE and the remaining budgets. Our framework allows for both: (1) a clear separation of the effect of individual uncertain factors affecting TCRE and the RCB, as well as (2) an estimate of the combined effect of different uncertain factors on the overall distribution of TCRE and the RCB. We derive uncertainty estimates from a combination of observation-based and modelled quantities, as well as from the subset of future emission scenarios that reach netzero $\mathrm{CO}_{2}$ emissions before 2100 -i.e. those that include the rapid $\mathrm{CO}_{2}$ emissions reductions required to meet the goals of the Paris Agreement. Furthermore, we distinguish here between geophysical uncertainty (associated with uncertain physical or biogeochemical processes in the climate system) and socioeconomic uncertainty (associated with human socioeconomic systems and decision-making processes). We characterise these two types of uncertainties differently in our framework. The geophysical uncertainty can be represented quantitatively by probability distributions reflecting current scientific knowledge. However, the socioeconomic uncertainty is not well suited to be quantified within a formal probability framework owing to its dependence on collective and individual human decision-making processes, as well as subjective choices and perceptions of decision-makers.
In the framework presented here, we define the RCB for a given temperature limit as a function of five input parameters and their respective distributions. The first two input parameters (anthropogenic warming to date, and cumulative historical $\mathrm{CO}_{2}$ emissions) are derived from observation-based data, and the third (the current non- $\mathrm{CO}_{2}$ fraction of total anthropogenic forcing) can be estimated from observationally-constrained model simulations. Together, these three parameters integrate the effects of geophysical uncertainty on the TCRE and its distribution. The fourth geophysical parameter (the unrealised warming from past $\mathrm{CO}_{2}$ emissions) is included to allow us to estimate carbon budgets associated with ambitious mitigation scenarios leading to net-zero $\mathrm{CO}_{2}$ emissions. In such scenarios, the TCRE alone may not provide a robust estimate of the $\mathrm{CO}_{2}$-induced warming ${ }^{21}$ as it does not account for the effect of shifting patterns of warming associated with temperature stabilisation, nor feedbacks that manifest fully on longer time scales, such as permafrost carbon release. The final input parameter (non- $\mathrm{CO}_{2}$ fraction of total anthropogenic forcing at the time of net-zero $\mathrm{CO}_{2}$ emissions) captures future non- $\mathrm{CO}_{2}$ forcing uncertainty. This future forcing parameter varies with the uncertainty in the forcing response to a specified level of non- $\mathrm{CO}_{2}$ emissions as well as the effect of socioeconomic pathway uncertainty associated with mitigation choices that influence the level of future non- $\mathrm{CO}_{2}$ emissions.

We first express the TCRE as a function of the current anthropogenic contribution to observed warming $\left(\Delta T_{\text {anth }}\right)$, the current non- $\mathrm{CO}_{2}$ fraction of total anthropogenic forcing $\left(f_{n c}\right)$ and historical cumulative $\mathrm{CO}_{2}$ emissions $(E)$ (see 'Methods' section for details of the derivation, and Table 1 for description of parameters):

$$
\text { TCRE }=\frac{\Delta T_{\text {anth }}}{E} \times\left(1-f_{n c}\right) .
$$

Using this TCRE relationship (Eq. (1)), we then derive an expression for the total carbon budget (TCB) associated with a given temperature limit $\left(\Delta T_{\text {lim }}\right)$, defined as the total $\mathrm{CO}_{2}$ emissions from the pre-industrial reference period until the time that $\mathrm{CO}_{2}$ emissions reach net-zero:

$$
T C B=E \times\left(\frac{\Delta T_{\text {lim }}-\Delta T_{Z E C}}{\Delta T_{\text {anth }}}\right) \times\left(\frac{1-f_{n c}^{*}}{1-f_{n c}}\right) .
$$

Additional parameters in Eq. (2) represent the potential unrealised warming from past $\mathrm{CO}_{2}$ emissions, also referred to as the Zero-Emission Commitment $\left(\Delta T_{Z E C}\right)$, and the expected non$\mathrm{CO}_{2}$ fraction of total anthropogenic forcing at the time that $\mathrm{CO}_{2}$ emissions reach net-zero $\left(f_{n c}^{*}\right)$ (see 'Methods' section for details of derivation).

Conceptually, this equation (2) for the TCB can be understood as a function of three terms: (1) cumulative historical $\mathrm{CO}_{2}$ emissions $(E)$; (2) the available future warming between presentday and the temperature target $\left(\frac{\Delta T_{\text {lim }}-\Delta T_{Z E C}}{\Delta T_{\text {anth }}}\right)$; and (3) the timeevolving non- $\mathrm{CO}_{2}$ contribution to temperature change, as represented by the ratio of future to present-day forcing fractions $\left(\frac{1-f_{n c}^{*}}{1-f_{n c}}\right)$. Finally, from Eq. (2), the RCB (defined as the total $\mathrm{CO}_{2}$ emissions from present day until the time that $\mathrm{CO}_{2}$ emissions reach net-zero, consistent with global temperatures reaching a desired warming level) can be calculated by subtracting historical $\mathrm{CO}_{2}$ emissions from the total budget, to arrive at:

$$
R C B=E \times\left(\left(\frac{\Delta T_{\text {lim }}-\Delta T_{Z E C}}{\Delta T_{\text {anth }}}\right)\left(\frac{1-f_{n c}^{*}}{1-f_{n c}}\right)-1\right) .
$$

We used Eqs. (1) and (3) to obtain the distribution of the TCRE and RCBs, respectively, by randomly sampling the input distributions (summarised in Table 1, and detailed in 'Methods' section and Supplementary Tables S1 and S2). We estimated the 


\begin{tabular}{|c|c|c|}
\hline Parameter & Description & Main case values \\
\hline$\Delta T_{\text {anth }}$ & $\begin{array}{l}\text { Anthropogenic warming in the year } 2019 \text { (with respect to the } \\
\text { 1850-1900 baseline, as in SR1.5) }\end{array}$ & $\begin{array}{l}\text { Median: } 1.18^{\circ} \mathrm{C} \\
5-95 \% \text { range: } 1.05-1.41^{\circ} \mathrm{C}\end{array}$ \\
\hline$E$ & $\begin{array}{l}\text { Cumulative } \mathrm{CO}_{2} \text { emissions from fossil fuels and land use (from } \\
1870 \text { to the end of 2019) }\end{array}$ & $\begin{array}{l}\text { Median: } 2350 \mathrm{GtCO}_{2} \\
\text { 5-95\% range: } 1960-2745 \mathrm{GtCO}_{2}\end{array}$ \\
\hline$f_{n c}$ & $\begin{array}{l}\text { Historical non- } \mathrm{CO}_{2} \text { forcing fraction (mean ratio of non- } \mathrm{CO}_{2} \text { to total } \\
\text { anthropogenic radiative forcing for } 1990-2019 \text { ) }\end{array}$ & Median value: $0.14,5-95 \%$ range: -0.11 to 0.33 \\
\hline$f_{n c}^{*}$ & $\begin{array}{l}\text { Future non- } \mathrm{CO}_{2} \text { forcing fraction (mean ratio of non- } \mathrm{CO}_{2} \text { to total } \\
\text { anthropogenic radiative forcing for } 30 \text { years prior to the year of net- } \\
\text { zero } \mathrm{CO}_{2} \text { emissions in each scenario). }\end{array}$ & $\begin{array}{l}\text { Treated as a linear function } f_{n c}^{*}=0.3081 f_{n c}+0.14+\text { offset based on } \\
\text { the regression line shown in Fig. } 3 \text { with a constant offset of } 0 \text { (main } \\
\text { case), or } \pm 0.05 \text { (reflecting the 5-95th range across all scenarios) }\end{array}$ \\
\hline$\Delta T_{\text {ZEC }}$ & $\begin{array}{l}\text { Zero-Emission Commitment (temperature increase or decrease } 50 \\
\text { years after zero emissions from the point that total emissions reach } \\
2750 \text { or } 3670 \mathrm{GtCO}_{2} \text { in the } 1 \% \text { per year } \mathrm{CO}_{2} \text { increase scenario) }\end{array}$ & Median: $0^{\circ} \mathrm{C} 5-95 \%$ range: -0.30 to $0.30^{\circ} \mathrm{C}$ \\
\hline$\Delta T_{\lim }$ & $\begin{array}{l}\text { Global mean warming target (human-induced warming, free from } \\
\text { influences of forced or unforced natural climate variability) } 27,28\end{array}$ & $1.5^{\circ} \mathrm{C}$ (or $1.75^{\circ} \mathrm{C}$ and $2.0^{\circ} \mathrm{C}$ in Supplementary Material) \\
\hline
\end{tabular}

distribution of $\Delta T_{\text {anth }}$ for the year 2019 using the method of ref. ${ }^{22}$, based on the average of the three observational temperature datasets with full spatial coverage. The distributions for $E$ and $\triangle T_{Z E C}$ are based on Gaussian distributions fitted to cumulative $\mathrm{CO}_{2}$ emissions from 1870 to 2019 from the Global Carbon Project $^{23}$, and model-simulated Zero Emissions Commitment (ZEC) values from the coordinated model intercomparison project $\mathrm{ZECMIP}{ }^{24}$, respectively. We represent the current non- $\mathrm{CO}_{2}$ forcing fraction as a 30-year average from 1990 to 2019, and computed the uncertainty range for $f_{n c}$ using the FaIR emulator ${ }^{18}$ driven by scenarios from SR1.5 database ${ }^{25,26}$. Future non- $\mathrm{CO}_{2}$ forcing fraction $\left(f_{n c}^{*}\right)$ values are defined as a linear function of $f_{n c}$ to reflect the range across SR1.5 scenarios that is caused by geophysical forcing uncertainty, for the 30 years prior to the time of net-zero $\mathrm{CO}_{2}$ emissions in each scenario. Finally, we applied a constant offset to this function to capture the scenario-based variation (socioeconomic uncertainty) in the relationship between current and future non- $\mathrm{CO}_{2}$ forcing fractions (see 'Methods' section).

\section{Results and discussion}

Observation-based estimate of the TCRE distribution. Our median TCRE estimate is $0.44{ }^{\circ} \mathrm{C}$ per $1000 \mathrm{GtCO}_{2}$, with a 5-95\% range of $0.32-0.62{ }^{\circ} \mathrm{C}$ per $1000 \mathrm{GtCO}_{2}$ (Fig. 1; 'Main case'; Supplementary Table S3). This is a similar median estimate, though with a much narrower range as compared to the assessed AR5 range ${ }^{29}$ that was used in SR1.5 (median $0.44{ }^{\circ} \mathrm{C}$ per $1000 \mathrm{GtCO}_{2}$; 1-sigma range $0.22-0.68^{\circ} \mathrm{C}$; Fig. 1a grey distribution). Our $5-95 \%$ TCRE range also agrees well with previously reported TCRE estimates (Refs. 11,15,18,30-42; Fig. 2c). We do however find a stronger constraint on the left-hand side of the distribution (low TCRE values, with sharply increasing probability above $0.25^{\circ} \mathrm{C} /$ $1000 \mathrm{GtCO}_{2}$ ), while the right-hand side of this distribution has a wider tail. This right-skewed distribution shape of our observationally-constrained TCRE estimate is physically related to the possibility of a large negative aerosol forcing ${ }^{40}$.

We further assessed the sensitivity of our TCRE estimate to varying the three input parameters. The TCRE distribution is most sensitive to changes in the current non- $\mathrm{CO}_{2}$ forcing $\left(f_{n c}\right)$ parameter (Eq. (1)). Assuming zero uncertainty in $f_{n c}$ results in a TCRE 5-95\% range that is 33\% narrower, whereas assuming zero uncertainty in $E$ or $\Delta T_{\text {anth }}$ decreases the TCRE $5-95 \%$ range by only $13 \%$ and $10 \%$, respectively. Given that the dominant contribution of $f_{n c}$ uncertainty is from aerosol forcing uncertainty, where a stronger aerosol forcing implies a smaller total non- $\mathrm{CO}_{2}$ forcing and therefore a larger TCRE, we can expect that better constraining observed aerosol forcing would have a large impact on our median TCRE estimate and its distribution.

Remaining carbon budgets integrating key geophysical uncertainties. Our median RCB for $1.5^{\circ} \mathrm{C}$ is $440 \mathrm{GtCO}_{2}$ from 2020 onwards, representing a $50 \%$ chance of stabilising warming at or below $1.5^{\circ} \mathrm{C}$. (Note that we report remaining budgets rounded to the nearest $10 \mathrm{GtCO}_{2}$, following SR1.5). The corresponding budget for a $67 \%$ chance of remaining below the target is 230 $\mathrm{GtCO}_{2}$ from the year 2020 onwards (Fig. 2a; see Supplementary Fig. S4 for 1.75 and $2{ }^{\circ} \mathrm{C}$ budgets). Our median and $67 \%$ budget estimates for $1.5^{\circ} \mathrm{C}$ are smaller by $60 \mathrm{GtCO}_{2}$ and $110 \mathrm{GtCO}_{2}$, respectively, than those reported by SR1.5 (table 2.2 therein, adjusted to 2020 onwards using observed $\mathrm{CO}_{2}$ emissions for 2018-2019). Our lower median budget compared to SR1.5 can be explained by the explicit representation of a broader range of sources of geophysical uncertainty in our framework; indeed, our "no uncertainty" median estimate shown in Fig. 2b is almost equal to the SR1.5 median value.

In our estimate of the RCB and its distribution, we have therefore internalised the sources of geophysical uncertainty which were reported separately by SR1.5: (1) current non- $\mathrm{CO}_{2}$ forcing uncertainty is now explicitly represented by uncertainty in our parameter $f_{n c} ;(2)$ future non- $\mathrm{CO}_{2}$ forcing uncertainty is internally consistent with historical uncertainty such that higher and lower values of $f_{n c}$ are paired with correspondingly higher and lower values of future $f_{n c}^{*}$; (3) recent emission uncertainty is folded into the uncertainty in $E$; (4) historical temperature uncertainty is captured by our $\Delta T_{\text {anth }}$ distribution; (5) our TCRE distribution reflects the distributions of the input parameters and is therefore implicit in the remaining budget distribution; (6) adjustments for under-represented feedbacks in ESMs are embedded in our method, given that our TCRE estimate is derived from observed quantities that include the effect of all relevant processes operating in the Earth system; and (7) we have additionally included uncertainty in $\Delta T_{Z E C}$ which was only recently quantified ${ }^{24}$ and thus not included as a quantified uncertainty in the SR1.5 (or any other) carbon budget analysis. On near-term decadal time scales relevant to achieving the $1.5^{\circ} \mathrm{C}$ or $2.0^{\circ} \mathrm{C}$ target, this $\Delta T_{Z E C}$ term also accounts for the additional changes in global mean temperature due to feedbacks, such as permafrost carbon release ${ }^{24}$ that are not captured by the TCRE but may contribute to warming on longer time scales.

The integration of uncertainties and use of observational constraints on our input parameters has allowed us to generate a considerably narrower spread in the estimate of the RCB 

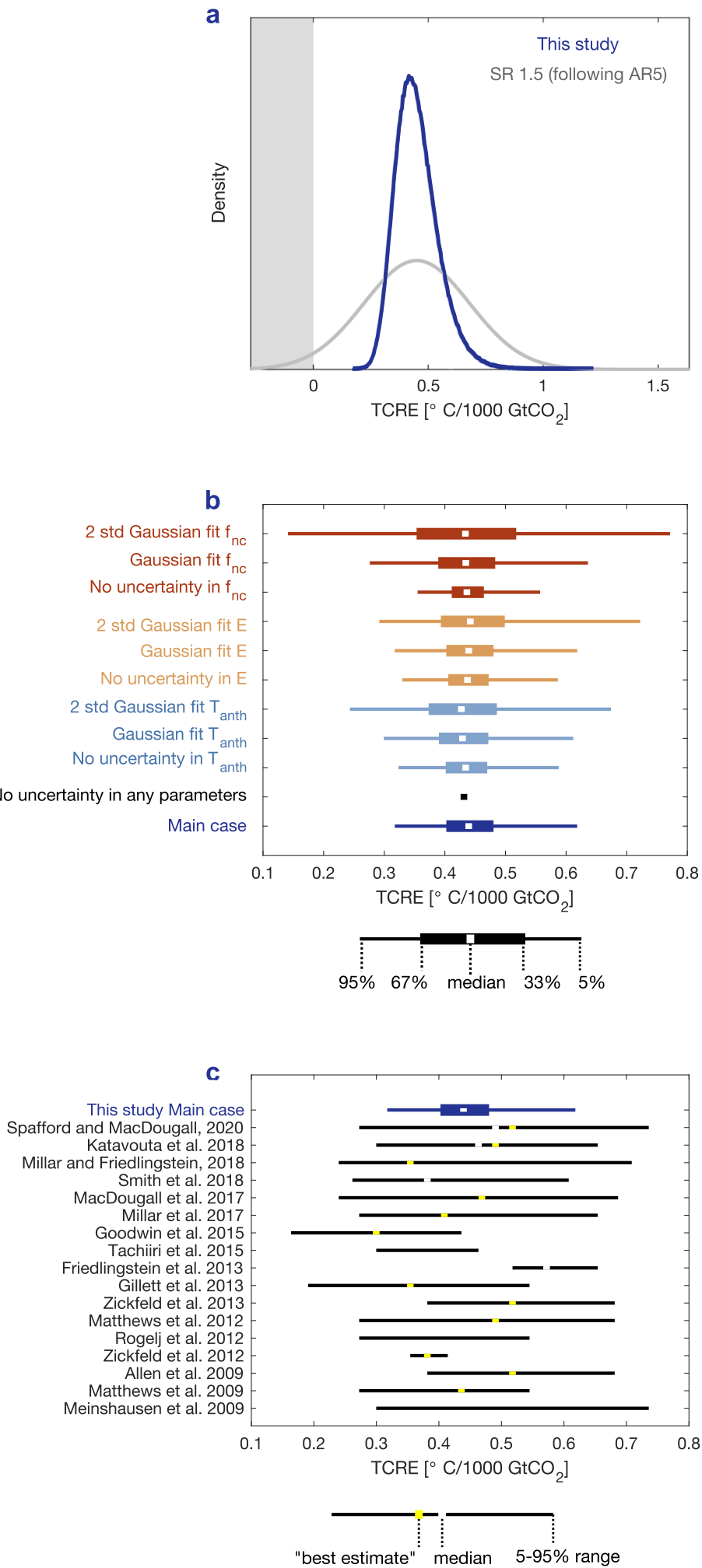

Fig. 1 Distributions and resulting ranges of the transient climate response to cumulative $\mathbf{C O}_{\mathbf{2}}$ emissions (TCRE). a TCRE distribution (blue; 'Main case'), compared with a Gaussian fit to the TCRE distribution used in SR1.5 (grey). The grey shaded rectangle in a shows the unphysical regime of negative TCRE values. $\mathbf{b}$ Sensitivity analysis of the TCRE range to increasing or decreasing uncertainty in the input distributions of individual parameters. Box plots indicate the median value (white mark), 33rd-67th percentile range (thick line) and 5-95\% range (thin lines), as labelled. Here, 'Gaussian fit' case refers to a Gaussian approximation of the empirical parameter distribution, and the ' 2 std Gaussian fit' case refers to that same distribution with doubled standard deviation to show the effect of inflated uncertainty range in a like-for-like manner across the three parameters (see also Supplementary Fig. S2 and

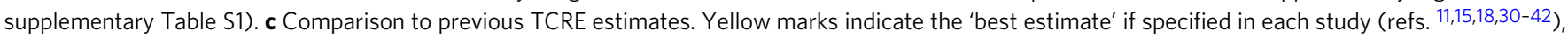
white marks indicate the median estimate, and lines indicate the $5-95 \%$ range. 
a

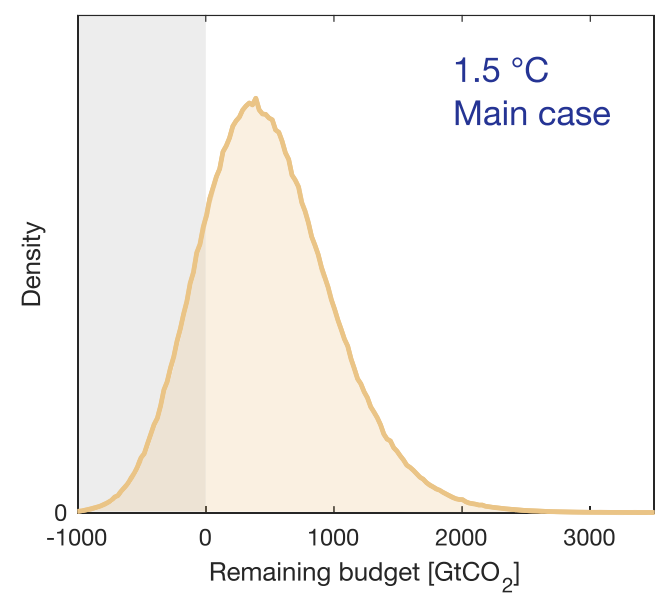

b
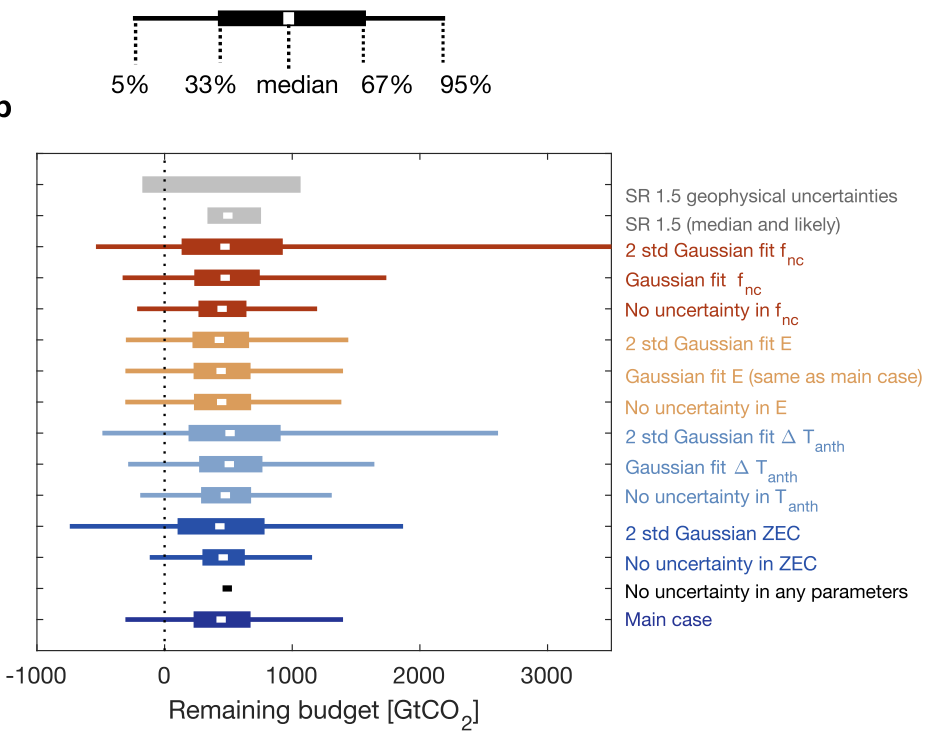

Fig. 2 Distribution of the remaining carbon budget for $1.5^{\circ} \mathrm{C}$ for emissions from the beginning of the year 2020 onwards, and the effect of related geophysical uncertainties. a Distribution of the remaining carbon budget for $1.5^{\circ} \mathrm{C}$ for the "Main case", with a median estimate of $440 \mathrm{GtCO}$ and a $33 \mathrm{rd}$ percentile of $230 \mathrm{GtCO}_{2}$ (representing a $50 \%$ and $67 \%$ chance of remaining below $1.5^{\circ} \mathrm{C}$, respectively); $\mathbf{b}$ Sensitivity of the $1.5^{\circ} \mathrm{C}$ remaining budget and its range to increased or decreased uncertainty in the input distributions of individual parameters (coloured bars as labelled on vertical axis) and comparison to the SR1.5 estimates (grey bars, where the upper grey bar represents the total range spanned by additional uncertainties that were not included in the median and 33rd-67th TCRE percentile range shown in the lower grey bar). SR1.5 numbers illustrated here are adjusted downwards (based on ref. ${ }^{23}$ ), to represent remaining budgets from the beginning of the year 2020, rather than 2018 as originally reported. Equivalent figures for 1.75 and $2{ }^{\circ} \mathrm{C}$ budgets are shown in Supplementary Fig. S4. The box plots indicate the median value, the 33-67\% range, and the 5-95\% range, as labelled.

compared to that provided by SR1.5 (see grey bars on Fig. $2 \mathrm{~b}$ showing the SR1.5 budget distribution: lower grey bar for the likely estimate of the remaining budget based on spread in TCRE alone, and the upper grey bar for the sum of all additional geophysical uncertainties as reported by SR1.5). It is worth noting however, that the spread of our RCBs estimate does include negative values, with a $17 \%$ chance that the RCB for $1.5^{\circ} \mathrm{C}$ is less than zero (i.e. is already exceeded). This outcome could arise due to current and/or unrealised future warming being at the higher end of their respective distributions, or in the case that the current non- $\mathrm{CO}_{2}$ forcing fraction is small or negative owing to very strong current aerosol forcing. In this case, we would expect $1.5^{\circ} \mathrm{C}$ to be exceeded even in the absence of additional emissions, and any future emissions between now and the time of net-zero $\mathrm{CO}_{2}$ emissions would cause temperatures to rise further above this threshold.

Of the four uncertain geophysical parameters in Eq. (3), the current non- $\mathrm{CO}_{2}$ forcing fraction $\left(f_{n c}\right)$, anthropogenic warming $\left(\Delta T_{\text {anth }}\right)$ and unrealised warming $\left(\Delta T_{Z E C}\right)$ all had a substantial effect on our RCB distribution (Fig. 2b). Setting the uncertainty of each parameter to zero increased the $67 \% \mathrm{RCB}$ for $1.5^{\circ} \mathrm{C}$ from 230 to 260,290 and $300 \mathrm{GtCO}_{2}$ for $f_{n c}, \Delta T_{\text {anth }}$ and $\Delta T_{Z E C}$, respectively (Supplementary Table S4). Interestingly, decreasing the uncertainty in historical cumulative emissions $(E)$ had almost no effect on the spread of the RCB distribution. This can be understood as a result of two opposing effects. First, higher $E$ would decrease the estimated TCRE, leading to an increase in the estimate of the TCB from Eq. (2). However, higher $E$ also means that a larger portion of the total budget has already been emitted, which consequently decreases the available future emissions. The result is a remaining budget estimate that is almost insensitive to the uncertainty associated with historical cumulative emissions.

Effect of socioeconomic uncertainties on the remaining carbon budget. The results presented above (and shown in Fig. 2) integrate the effect of geophysical uncertainties on the RCB. However, earlier studies ${ }^{2,14}$ also highlighted the importance of socioeconomic uncertainties that affect future pathways of non$\mathrm{CO}_{2}$ forcing. This source of uncertainty can be explored in our framework by adjusting the relationship between current $\left(f_{n c}\right)$ and future $\left(f_{n c}^{*}\right)$ non- $\mathrm{CO}_{2}$ forcing fractions to reflect the variation in non- $\mathrm{CO}_{2}$ forcing across future scenarios that is caused by socioeconomic uncertainty in future emission pathways. This relationship between $f_{n c}$ and $f_{n c}^{*}$ at the time of net-zero emissions is shown in Fig. 3a, where each grey dot represents an individual scenario available in the SR1.5 scenario database ${ }^{25,26}$, and the isolines indicate the RCB for each combination of $f_{n c}$ and $f_{n c}^{*}$. Here, $f_{n c}$ represents geophysical uncertainty associated with the estimate of today's non- $\mathrm{CO}_{2}$ forcing (shown by the horizontal spread of the grey points; Fig. 3a). In contrast, $f_{n c}^{*}$ represents both geophysical uncertainty associated with future forcing, and socioeconomic uncertainty associated with future non- $\mathrm{CO}_{2}$ emissions scenarios (represented by the vertical spread of grey points; Fig. 3a).

To separate the geophysical and socioeconomic contributions to the spread in $f_{n c}^{*}$, we first used the positive correlation between current $f_{n c}$ values and future $f_{n c}^{*}$ values (thick solid line) to propagate current forcing uncertainty onto the future scenarios, such that each $f_{n c}$ value is mapped to a unique and consistent $f_{n c}^{*}$ value (based on the scenarios from SR1.5 database ${ }^{25,26}$ ). This approach avoids using combinations of current and future forcing values that are outside the SR1.5 scenario range, and captures the effect of both historical and future non- $\mathrm{CO}_{2}$ forcing uncertainty associated with the "average" future scenario (this is the approach used for the "main case" results shown in Fig. 2). To assess the effect of socioeconomic scenario uncertainty, we then used the vertical spread of $f_{n c}^{*}$ values around the best-fit line as a representation of the scenario-based variation in $f_{n c}^{*}$ that is mostly independent of the geophysical variation in $f_{n c}$. We 
a
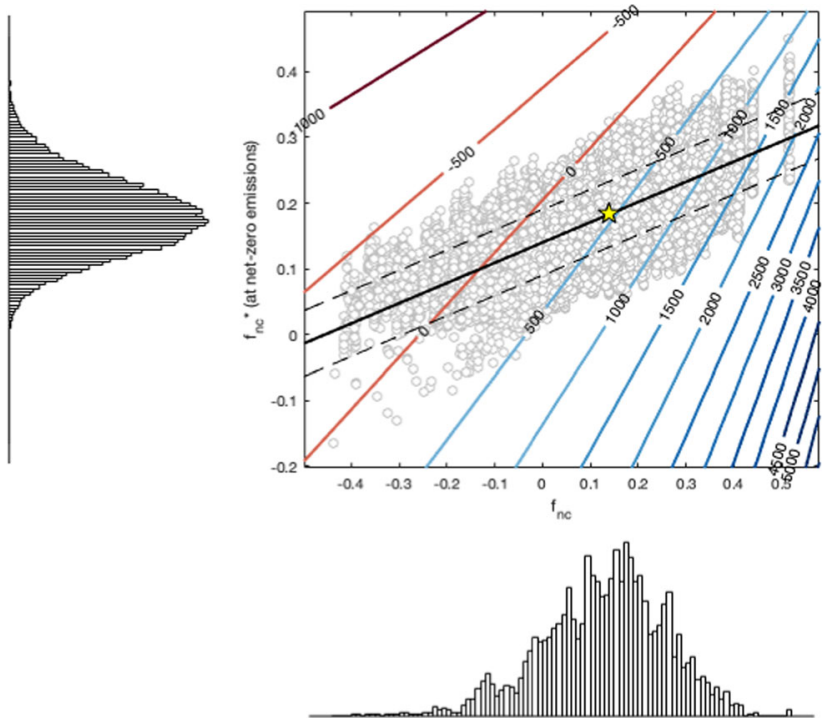

b
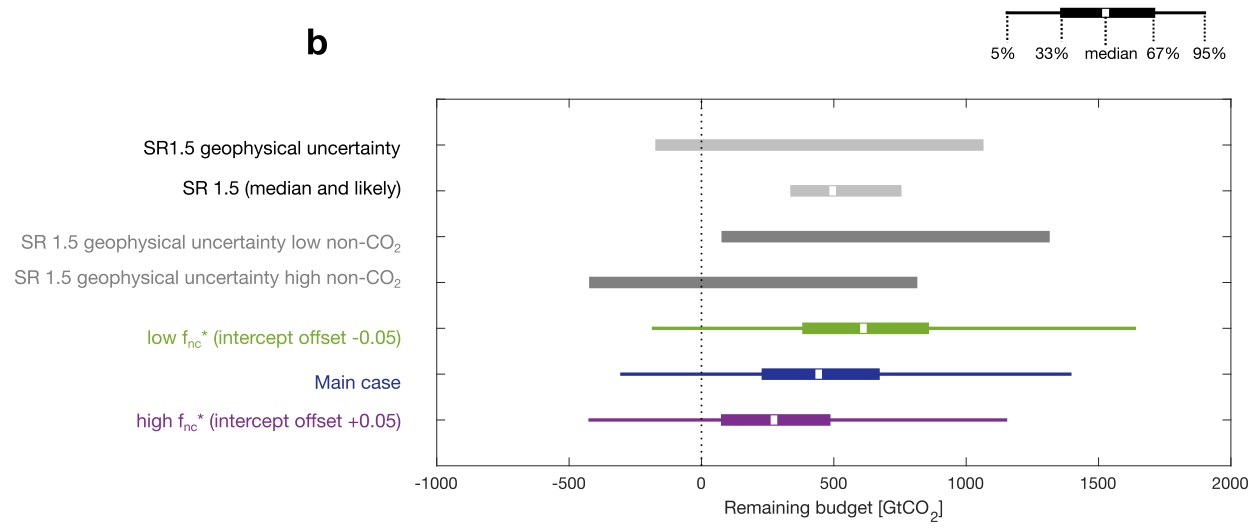

Fig. 3 Changes in remaining carbon budgets due to socioeconomic uncertainty affecting future non- $\mathrm{CO}_{2}$ forcing. a Remaining carbon budgets as a function of future $\left(f_{n c}^{*}\right)$ and current $\left(f_{n c}\right)$ non- $\mathrm{CO}_{2}$ forcing fractions. Isolines (in $\mathrm{GtCO}_{2}$ ) indicate the remaining budget associated with each combination of $f_{n c}$ and $f_{n c^{\prime}}^{*}$ and the yellow star marks the median budget for the "main case" shown in Fig. 2. Circle markers indicate the pairs of $f_{n c}^{*}$ and $f_{n c}$ values from each net-zero $\mathrm{CO}_{2}$ scenario in the SR1.5 scenario database, with their respective histograms shown along the $x$ and $y$-axis. In both cases, we used a 30-year average of forcing fractions, covering the 30 years prior to 2019 (for $f_{n c}$ ) and prior to the year of net-zero $\mathrm{CO}_{2}$ emissions (for $f_{n c}^{*}$ ). The black line shows the linear fit (ordinary least squares) to all the circles, with a \pm 0.05 offset in the intercept (dashed lines). The resulting remaining budgets for each offset are shown in $\mathbf{b}$, representing the effect of scenario uncertainty on the range of $f_{n c}^{*}$ values. $\mathbf{b}$ Changes in the median, likely and 5-95\% remaining budgets as a result of an increase or decrease in the difference between the current and future non- $\mathrm{CO}_{2}$ forcing fraction (coloured bars) compared to the assessed scenario uncertainty effect in SR1.5 (dark grey bars).

therefore adjusted the intercept of the regression line using offset values of \pm 0.05 which reflect the $5-95 \%$ spread across best-fit lines to each individual scenario in the ensemble (see 'Methods' section). In doing so, we are able to assess the sensitivity of the RCB estimate to the portion of future non- $\mathrm{CO}_{2}$ forcing fraction variation that is caused by socioeconomic uncertainties affecting future non- $\mathrm{CO}_{2}$ emission pathways.

This socioeconomic scenario uncertainty results in a substantial change in the RCB (Fig. 3b). Future non- $\mathrm{CO}_{2}$ forcing fraction values that are 0.05 higher (vertical offset shown by dashed line, Fig. 3a) decrease the remaining budget distribution for $1.5^{\circ} \mathrm{C}$ by $170 \mathrm{GtCO}_{2}$, causing its median value to decrease to $270 \mathrm{GtCO}_{2}$. Conversely, if $f_{n c}^{*}$ values are 0.05 lower, the RCB increases by the same amount and its median becomes 610 $\mathrm{GtCO}_{2}$. These changes in the median remaining budget (based on plausible values of $f_{n c}^{*}$ resulting from scenario variation) are smaller than the estimated uncertainty in the remaining SR1.5 budget for $1.5^{\circ} \mathrm{C}$ due to non- $\mathrm{CO}_{2}$ scenario variation of \pm 250 $\mathrm{GtCO}_{2}$ (SR1.5, table 2.2. therein, represented by the two dark grey bars in Fig. $3 b$ ). We are therefore able to provide here a robust quantitative basis that both supports and constrains the SR1.5 assessment of how future non- $\mathrm{CO}_{2}$ emissions will affect the spread of the RCB.

\section{Implications of incorporating uncertainties into TCRE and remaining carbon budget estimates}

Here we explicitly integrated of a full spectrum of geophysical uncertainties into our TCRE and RCB estimates. The resulting TCRE distribution is consistent with the TCRE range used by SR1.5, but narrower, and more constrained at lower values (which follows from the empirical distributions of anthropogenic warming and $\left(1-f_{n c}\right)$ that are also more constrained at lower 
values). Our RCBs have a similar range as those reported in SR1.5, despite including a considerably larger set of uncertain processes. SR1.5 reported only the uncertainty in TCRE as an integrated part of the RCB uncertainty (reporting additional sources of uncertainty separately). Our framework, on the contrary, integrates these sources of geophysical uncertainty into a single distribution of the RCB. The overall uncertainty in our estimate of the RCB for future temperature targets is more constrained than the sum of all sources of uncertainty reported by SR1.5.

We show further that estimates of the remaining budget can be affected by mitigation scenario choices that determine the difference between future $\left(f_{n c}^{*}\right)$ and current $\left(f_{n c}\right)$ non- $\mathrm{CO}_{2}$ forcing, and provide an alternative quantification compared to that reported by SR1.5. Scenarios with higher $f_{n c}^{*}$ values are associated with substantially lower RCBs. This effect would be particularly pronounced in the case of a small or negative current $f_{n c}$ (such as would be associated with a strongly negative current aerosol forcing) which could plausibly lead to a large future $f_{n c}^{*}$ value as a result of decreased aerosol emissions from decreased fossil fuel use. Similarly, failure to mitigate non- $\mathrm{CO}_{2}$ greenhouse gas emissions, such as methane from sources other than fossil fuels would lead to an increase in the future non- $\mathrm{CO}_{2}$ forcing fraction. In all cases, the estimates of RCBs consistent with keeping warming well-below 2 or $1.5^{\circ} \mathrm{C}$ as indicated in the UN Paris Agreement imply a strong limit on allowable future $\mathrm{CO}_{2}$ emissions, and highlight that immediate measures are required to bring down global $\mathrm{CO}_{2}$ emissions to net zero in the coming decades. Our results also illustrate that human choices regarding how stringently we reduce non- $\mathrm{CO}_{2}$ emissions can markedly decrease or increase the size of the RCB and affect the overall global decarbonisation challenge $e^{43}$.

The framework described here presents a tool for exploring how the RCB distribution is affected by changes in assumptions and uncertainties in each of its determining components. We note that this framework is subject to several assumptions. First, we assume that the TCRE (as estimated from present-day observations) is the same as the TCRE that would be estimated at the time $1.5^{\circ} \mathrm{C}$ is reached in a scenario of continued increasing emissions. This assumption is supported by many previous studies which have shown that in Earth System Models (ESMs), the TCRE is a good predictor of $\mathrm{CO}_{2}$-induced temperature changes over this range of warming levels as well as across a range of different emission scenarios $15,29,32,44,45$.

Second, we assume that all relevant feedbacks (including those not well represented by current models, such as permafrost carbon loss or methane release from wetlands) are reflected in the observational data that we have used to constrain the TCRE. We assume further that contributions from these feedbacks will not accelerate sufficiently over the next few decades as to change the observation-based TCRE estimate. This assumption is supported by recent analyses which have shown that the magnitude of the permafrost carbon feedback scales with cumulative $\mathrm{CO}_{2}$ emissions, suggesting that an observationally-constrained TCRE will remain a reasonable estimate of the climate response to future $\mathrm{CO}_{2}$ emissions ${ }^{8}$. We recognise, however, the potential for nonlinear climate responses to cumulative $\mathrm{CO}_{2}$ emissions to become larger at higher warming levels. In addition, for higher warming levels, the possibility of tipping elements in the climate system increases ${ }^{46}$. Our framework is therefore best suited to estimating the remaining budget for warming levels below $2{ }^{\circ} \mathrm{C}$ during this century.

Third, we have represented the $\mathrm{CO}_{2}$-induced temperature change at the time of net-zero $\mathrm{CO}_{2}$ emissions as a function of both the TCRE and the ZEC. Here, the TCRE represents the transient warming from a given amount of cumulative emissions, and the ZEC reflects the additional warming or cooling that could occur in a scenario with rapidly decreasing $\mathrm{CO}_{2}$ emissions as a result of the transition from transient to equilibrium $\mathrm{CO}_{2}$-induced warming. This formulation allows for the lagged response of permafrost and other longer timescale feedbacks to manifest during the time that global $\mathrm{CO}_{2}$ emissions decrease to net-zero, and for the uncertainty in this response to be captured by uncertainty in the $\Delta T_{Z E C}$ parameter. This formulation also accounts for the so-called "pattern effect", whereby the strength of physical climate feedbacks is expected to increase over time as a result of changing warming patterns ${ }^{47-49}$. However, this pattern effect may also lead to deviations from a linear forcing-temperature relationship over time, which we have not accounted for in the representation of non- $\mathrm{CO}_{2}$ forcing in our framework. While we expect nonlinearities associated with the pattern effect or with feedbacks, such as permafrost thaw to be relatively small for temperatures below $2{ }^{\circ} \mathrm{C}$, further research is needed to quantify if such effects would introduce further adjustments of the RCBs in our framework.

Finally, we assume that the temperature response is approximately proportional to effective radiative forcing, and therefore, that the non- $\mathrm{CO}_{2}$ warming contribution can be approximated from the non- $\mathrm{CO}_{2}$ forcing fraction $\left(f_{n c}\right.$ and $f_{n c}^{*}$, for the present day and future, respectively $)^{50}$. As shown in Supplementary Fig. S5, the 30-year (1990-2019) average of $f_{n c}$ that we have used here is a good proxy for the non- $\mathrm{CO}_{2}$ warming fraction in the year 2019. Given that the non- $\mathrm{CO}_{2}$ forcing fraction has increased substantially over recent decades in response to decreasing or stable aerosol emissions with increasing $\mathrm{CO}_{2}$ forcing (see Supplementary Fig. S5), this suggests that there is about a 15-year lag between changing forcing fractions and the realised warming fraction associated with this change. Consequently, we expect there to also be a similar lag between future non- $\mathrm{CO}_{2}$ forcing changes and the resulting non- $\mathrm{CO}_{2}$ contribution to future warming. By selecting the 30 -year average preceding the year of net-zero $\mathrm{CO}_{2}$ emissions in each scenario, we expect that we are correctly estimating the non- $\mathrm{CO}_{2}$ contribution to observed warming at the net-zero year. However, our framework does not include any information or assumptions about what occurs after the net-zero year; clearly both the continuing trajectory of non$\mathrm{CO}_{2}$ forcing, combined with whether $\mathrm{CO}_{2}$ emissions remain at net-zero or become net-negative, will determine whether global temperatures successfully stabilise at the target temperature in subsequent years.

The framework we have described here allows for an estimate of the TCRE and its distribution by incorporating input parameters that can be derived from (and themselves constrained by) observational data. It also allows for more comprehensive and integrated treatment of uncertainties associated with estimates of the RCB. The resulting overall uncertainty in our estimates of the RCB for future temperature targets is substantially narrower than previous assessments. Our median estimate of the $1.5^{\circ} \mathrm{C} \mathrm{RCB}$ is consistent with a scenario of global $\mathrm{CO}_{2}$ emissions that reach netzero around the year 2040, emphasising the central requirement of rapid $\mathrm{CO}_{2}$ emission reductions to retain any reasonable chance of meeting this temperature target. Our framework also shows explicitly how uncertainty in each parameter contributes to the overall distribution of the RCB, and is able to quantify the effect of mitigation decisions that will determine the non- $\mathrm{CO}_{2}$ contribution to future temperature changes. We emphasise that carbon budget estimates will need to be continually updated as scientific knowledge, and on-going $\mathrm{CO}_{2}$ emissions and mitigation efforts progress over the coming years ${ }^{51}$. In particular, narrower constraints on the strength of current aerosol forcing and its 
potential to change as a result of decarbonisation or air pollution control efforts ${ }^{52,53}$ will be key to decreasing the overall uncertainty in estimates of the RCB. The new estimate and improved quantification of uncertainties provided here demonstrate that both $\mathrm{CO}_{2}$ and non- $\mathrm{CO}_{2}$ greenhouse gas emissions must be decreased as quickly as possible to maintain a possibility of not surpassing the global temperature goal of the Paris Agreement.

\section{Methods}

Transient climate response to cumulative $\mathrm{CO}_{2}$ emissions. The transient climate response to cumulative $\mathrm{CO}_{2}$ emissions (TCRE) is defined as the transient warming of the climate system per unit of $\mathrm{CO}_{2}$ emitted:

$$
T C R E=\frac{\Delta T_{\mathrm{CO}_{2}}}{E}
$$

where $\Delta T_{\mathrm{CO}_{2}}$ is the $\mathrm{CO}_{2}$-induced warming, and $E$ is the total historical $\mathrm{CO}_{2}$ emissions. The TCRE is usually formally estimated at the point of doubled $\mathrm{CO}_{2}$ in a $\mathrm{CO}_{2}$-only climate model simulation. However, given its time and scenario independence, the TCRE can also be estimated using observed quantities to estimate the $\mathrm{CO}_{2}$-only contribution to historical temperature change. Here, we approximate the historical temperature change caused by total historical $\mathrm{CO}_{2}$ emissions as:

$$
\Delta T_{C O 2}=\Delta T_{\text {anth }} \times \frac{F_{C O 2}}{F_{\text {anth }}}=\Delta T_{\text {anth }} \times\left(1-f_{n c}\right) .
$$

Here, $\Delta T_{\text {anth }}$ is an estimate of the anthropogenic contribution to observed warming. $\frac{F_{\mathrm{CO} 2}}{F_{2}}$ is the ratio of $\mathrm{CO}_{2}$ to total anthropogenic forcing, which we rewrite as $\left(1-f_{n c}\right)$, where $f_{n c}$ is the non- $\mathrm{CO}_{2}$ fraction of total anthropogenic effective radiative forcing (i.e. $f_{n c}$ is $\frac{F_{n o n-C O 2}}{F_{a n t h}}$, and $F_{a n t h}$ is a sum of $F_{\mathrm{CO}_{2}}$ and $F_{n o n-\mathrm{CO}_{2}}$ ). We can therefore estimate the TCRE as:

$$
T C R E=\frac{\Delta T_{\text {anth }}}{E} \times\left(1-f_{n c}\right) .
$$

Remaining carbon budgets. Rearranging Eq. (6), historical cumulative emissions can be expressed as:

$$
E=\frac{\Delta T_{\text {anth }}}{T C R E} \times\left(1-f_{n c}\right) .
$$

Similarly, the TCB associated with some future temperature target $\left(\Delta T_{\text {lim }}\right.$, e.g. 1.5 , 1.75 or $2.0^{\circ} \mathrm{C}$ of anthropogenic warming since the pre-industrial level (1850-1900); refs. ${ }^{1,2,4}$ ) can be expressed as:

$$
T C B=\frac{\Delta T_{\text {lim }}}{T C R E} \times\left(1-f_{n c}^{*}\right) .
$$

Here, $f_{n c}^{*}$ is now the future non- $\mathrm{CO}_{2}$ forcing fraction that occurs at the time that the temperature target is reached.

This formulation assumes that the TCRE is a robust predictor of $\mathrm{CO}_{2}$-induced warming between present-day and the time that the temperature target is reached. This has been shown by many previous studies to be a reasonable assumption in the case that emissions continue to increase ${ }^{15-17,32,44}$. However, this assumption may not hold for ambitious mitigation scenarios as a result of the transition from transient to equilibrium $\mathrm{CO}_{2}$-induced warming that would occur as $\mathrm{CO}_{2}$ emissions decrease to zero. As a result, Eq. (8) holds only for scenarios with increasing emissions which reach and then exceed the temperature limit. To generalise this to the case of decreasing emission scenarios, we therefore introduce an additional term $\left(\triangle T_{Z E C}\right)$ that represents the warming or cooling that would occur after $\mathrm{CO}_{2}$ emissions are set abruptly to zero from a scenario with increasing emissions ${ }^{24,54}$. This ZEC represents unrealised warming or cooling from past $\mathrm{CO}_{2}$ emissions only, and allows us to approximate the $\mathrm{CO}_{2}$-induced warming when emissions reach net-zero $\left(\Delta T_{\mathrm{CO}_{2}-\text { net-zero }}\right)$ as:

$$
\Delta T_{\mathrm{CO}_{2}-\text { net-zero }}=T C R E \times T C B+\Delta T_{Z E C}
$$

Incorporating this relationship into Eq. (8) results in the following equation for the TCB:

$$
T C B=\frac{\left(\Delta T_{\text {lim }}-\Delta T_{Z E C}\right)}{T C R E} \times\left(1-f_{n c}^{*}\right),
$$

where $\Delta T_{\text {lim }}$ represents the temperature target (e.g. $1.5,1.75$ or $2.0^{\circ} \mathrm{C}$ of anthropogenic warming since $1850-1900$, as before), but now this temperature change can be associated with a given TCB at the time that $\mathrm{CO}_{2}$ emissions reach net-zero.
Substituting Eq. (6) into Eq. (10) results in the following equation to calculate the TCB (included as Eq. (2) in the main manuscript):

$$
T C B=E \times\left(\frac{\Delta T_{\text {lim }}-\Delta T_{Z E C}}{\Delta T_{\text {anth }}}\right) \times\left(\frac{1-f_{n c}^{*}}{1-f_{n c}}\right) .
$$

Finally, the RCB for a given temperature limit is the difference between the above TCB (Eq. (11)) and the total historical $\mathrm{CO}_{2}$ emissions $E$. We therefore arrive at Eq. (3) in the main manuscript:

$$
R C B=E \times\left(\left(\frac{\Delta T_{\text {lim }}-\Delta T_{Z E C}}{\Delta T_{\text {anth }}}\right)\left(\frac{1-f_{n c}^{*}}{1-f_{n c}}\right)-1\right) .
$$

This framework therefore can be used to calculate the RCB as a function of the three parameters used to estimate the TCRE $\left(\Delta T_{a n t h}, E\right.$ and $\left.f_{n c}\right)$ and the two additional parameters $f_{n c}^{*}$ and $\Delta T_{Z E C}$.

Note that we have not included an adjustment to the RCB in our framework to represent the effect of so-called under-represented Earth system feedbacks (such as permafrost carbon cycle feedbacks). This adjustment was assessed in SR1.5 on the grounds that the TCRE values used in their analysis were derived largely from ESMs which did not include permafrost and other potentially important Earth system feedbacks. However, in our framework, we are estimating the TCRE from observed quantities rather than from ESMs. As a result, these observations should include the transient effect of all feedbacks that are currently operating in the real Earth system, including the effect of permafrost carbon loss. Furthermore, the inclusion of the ZEC parameter in our framework additionally allows for the slowresponse component of permafrost feedbacks to be captured as part the additional warming or cooling occurs in the transition from increasing to net-zero $\mathrm{CO}_{2}$ emissions.

Data sources for input parameters and sampling method. Here, we describe the methods and data sources used to derive the distribution of each input parameter used to estimate the TCRE and RCB (for details of each distribution see Supplementary Tables S1 and S2; Supplementary Figs. S1 and S2).

Historical cumulative $\mathrm{CO}_{2}$ emissions $(E)$ and their uncertainty $( \pm 1 \sigma$ range) for the period from 1870 to 2019 are taken from the 2019 Global Carbon Project estimate ${ }^{23}$, and include cumulative $\mathrm{CO}_{2}$ emissions from both fossil fuels and landuse change. This estimate is based on energy and industry statistics, as well as landuse book-keeping methods ${ }^{23}$. Here, we fitted a Gaussian distribution to the mean and 1 standard deviation range of $640 \pm 65 \mathrm{GtC}\left(2350 \pm 240 \mathrm{GtCO}_{2}\right)$ reported by ref. 23 .

For $\Delta T_{\text {anth }}$ we use the method of ref. ${ }^{22}$ to estimate the anthropogenic contribution to observed warming for the year 2019 (relative to the 1850-1900 base period), by removing natural variability and natural forcing contributions using a statistical model ${ }^{18}$. We used the mean of temperature observations from three datasets that are interpolated to a high spatial coverage (HadCRUT-CW ${ }^{55}$, GISTEMP $^{56}$ and Berkeley Earth ${ }^{57}$ ), resulting in a median estimate of $\Delta T_{\text {anth }}$ of $1.18^{\circ} \mathrm{C}$ in 2019 . This estimate is $0.06^{\circ} \mathrm{C}$ higher than that produced using the four observational datasets used by SR1.5 (GISTEMP, NOAA ${ }^{58}$, HadCRUT-CW and HadCRUT $^{59}$ ) owing to the incomplete spatial coverage in the HadCRUT and NOAA datasets. In addition, the most recent version of HadCRUT-CW includes an upward revision of observed temperature estimates due to improved algorithms to account for biases related to the transition in marine temperature measurement instruments ${ }^{60}$. Our distribution of $\Delta T_{\text {anth }}$ accounts for instrumental uncertainty in the HadCRUT dataset (which we assume is representative of instrumental uncertainty in other datasets). We note however that we do not account for other potential sources of uncertainty, such as those related to spatial interpolation methods or systematic instrumentation changes. We also do not explicitly account for uncertainty in dataset choice; rather we have selected observational temperature products that are based on different input measurements of SST and land surface temperature, thus providing three (mostly independent) lines of evidence for the estimates of the observed warming. Furthermore, using these spatially interpolated observational datasets means that our estimate of anthropogenic warming is a global mean surface temperature (GMST) metric that is only $0.03^{\circ} \mathrm{C}$ less than a global surface air temperature (GSAT) metric based on only air temperatures rather than blended air and surface ocean temperatures. We therefore argue that our representation of anthropogenic warming is a reasonable compromise between GMST and GSAT, and is also consistent with the temperature goal of the Paris Agreement $4,27,28,61$

The current non- $\mathrm{CO}_{2}$ forcing fraction $\left(f_{n c}\right)$ and its uncertainty are taken from an empirical distribution generated using the FaIR climate model emulator ${ }^{18}$, using updated forcing estimates for aerosols ${ }^{62}$ and for $\mathrm{CO}_{2}$ and methane ${ }^{63,64}$. We also used FaIR to estimate the future non- $\mathrm{CO}_{2}$ forcing fraction $\left(f_{n c}^{*}\right)$, so as to generate an internally consistent set of historical and future forcing fractions. We used 411 netzero $\mathrm{CO}_{2}$ emission scenarios from the SR1.5 scenario database ${ }^{25,26}$, and FaIR was run using a 1000-member perturbed parameter ensemble for climate sensitivity, carbon cycle feedbacks and present-day effective radiative forcing. These simulations were constrained to observed temperature changes, so that the scenario ensembles do not contain combinations of climate sensitivity and forcing that are incompatible with observed warming to date. We note that we could equally have 
used a different emulator (e.g. MAGICC ${ }^{20}$ ) for this purpose, though as shown in a recent intercomparison, there is little difference in the forcing distributions generated by different model emulators when driven by consistent forcings ${ }^{65}$.

A key assumption in our framework is that we can approximate the fraction of historical warming caused by non- $\mathrm{CO}_{2}$ emissions using their fractional effective radiative forcing, which should hold well as long as this forcing fraction does not change rapidly over time ${ }^{50}$. Given that the non- $\mathrm{CO}_{2}$ forcing fraction has increased over the past decade as a result of decreased aerosol emissions, using recent forcing fractions would overestimate the amount of warming at 2019 caused by non- $\mathrm{CO}_{2}$ emissions, and consequently underestimate the amount of warming caused by $\mathrm{CO}_{2}$ and the resulting TCRE. We therefore used the average non- $\mathrm{CO}_{2}$ forcing fraction for 1990-2019 as a more robust proxy for the 2019 non- $\mathrm{CO}_{2}$ fraction of anthropogenic warming (see Supplementary Fig. S5). The resulting median estimate for $f_{n c}$ is 0.14 , based on a combined non- $\mathrm{CO}_{2}$ forcing of $0.32 \mathrm{~W} / \mathrm{m}^{2}$ and total anthropogenic forcing of $2.30 \mathrm{~W} / \mathrm{m}^{2}$ (using the 1990-2019 multi-scenario constrained ensemble average). Of this combined non- $\mathrm{CO}_{2}$ forcing, aerosols contribute $-1.03 \mathrm{~W} / \mathrm{m}^{2}$ and non- $\mathrm{CO}_{2}$ greenhouse gases (including ozone and stratospheric water vapour from methane oxidation) contribute $+1.40 \mathrm{~W} / \mathrm{m}^{2}$.

Where $f_{n c}$ represents the geophysical uncertainty associated with current estimates of effective radiative forcing, $f_{n c}^{*}$ is meant to reflect uncertainty associated with future emission scenarios. In the SR1.5 scenario database however, future non- $\mathrm{CO}_{2}$ forcing values vary due to both current geophysical uncertainty (affecting the current non- $\mathrm{CO}_{2}$ forcing estimate) as well as future scenario variation in non$\mathrm{CO}_{2}$ emissions. To separate these two effects, we first defined $f_{n c}^{*}$ as a function of $f_{n c}$ based on the linear relationship across all scenarios that reached net-zero $\mathrm{CO}_{2}$ emissions during this century (see Table 1 and thick solid line in Fig. 3a indicating the ordinary least squares fit to all scenarios). This resulted in the equation for $f_{n c}^{*}$ used in the 'main case' and shown in Table 1:

$$
f_{n c}^{*}=0.3081 f_{n c}+0.14+\text { offset. }
$$

This linear approximation allows us to exclude combinations of $f_{n c}$ and $f_{n c}^{*}$ that are not covered by the range of SR1.5 scenarios, and to introduce a constant offset value to allow us vary the representation of $f_{n c}^{*}$ to reflect socioeconomic uncertainty independently from the geophysical uncertainty in $f_{n c}$. To estimate a representative offset value, we performed a similar fit to the ensemble of simulations for each individual emissions scenario from each model in the SR1.5 scenario database to gauge the portion of the vertical spread of points that can be explained purely by non- $\mathrm{CO}_{2}$ scenario variation. Based on the $5-95 \%$ range of the intercepts of across all individual scenario fits, we selected an offset value of \pm 0.05 to capture the plausible effect of non- $\mathrm{CO}_{2}$ scenario variation on the difference between current and future non- $\mathrm{CO}_{2}$ variation.

To quantify the effect of socioeconomic uncertainty associated with this set of ambitious mitigation pathways, we therefore adjusted the intercept of the maincase regression line by \pm 0.05 (dashed lines in Fig. 3a) to capture the variation in $f_{n c}^{*}$ across scenarios at a given value of $f_{n c}$. This offset therefore reflects human choices leading to socioeconomic uncertainty rather than geophysical uncertainty. Notably, this applies most strongly to emissions of short-lived climate forcers, where decreased emissions of methane and black carbon have the potential to decrease future non- $\mathrm{CO}_{2}$ forcing between now and the time of net-zero $\mathrm{CO}_{2}$ emissions and lead to larger RCBs. Similarly, decreased emissions of reflective aerosols will increase future non- $\mathrm{CO}_{2}$ forcing and lead to smaller RCBs. To reflect this element of human decision-making, we adopted the constant offset approach described above rather than including this socioeconomic uncertainty as part of the formal distribution of the RCB. We do note however that the vertical spread of all points in Fig. 3a is slightly larger than what can be explained by only scenario variation. This suggests that there may be an additional geophysical forcing uncertainty affecting future non- $\mathrm{CO}_{2}$ forcing, that reflects different possible mixes of individual species leading to the same total present-day non- $\mathrm{CO}_{2}$ forcing. We do not currently account for this additional geophysical uncertainty in our analysis, but acknowledge that it may introduce an additional shift of the median carbon budget (and an increase in spread) relative to the results presented in Fig. 2.

Finally, our distribution of $\Delta T_{7 E C}$ is based on the coordinated model intercomparison project ZECMIP ${ }^{24,54}$. In ZECMIP, ESMs and ESMs of Intermediate Complexity (EMICs) estimated the temperature change that occurred after $\mathrm{CO}_{2}$ emissions were set to zero at the point that cumulative emissions reached 750 and $1000 \mathrm{GtC}$ (i.e. 2750 and $3670 \mathrm{GtCO}_{2}$ ) in a scenario with prescribed $\mathrm{CO}_{2}$ concentration increases of $1 \%$ per year. We use the ZEC50 values from these experiments, which represents the change in temperature 50 years after zero emissions. For the $750 \mathrm{GtC}$ and $1000 \mathrm{GtC}$ experiments (which correspond approximately to the range of TCBs for temperature limits between 1.5 and $2{ }^{\circ} \mathrm{C}$ ), the mean ZEC50 across models was $-0.03^{\circ} \mathrm{C}$ (for 750 the GtC experiment) and $-0.06^{\circ} \mathrm{C}$ (for the $1000 \mathrm{GtC}$ experiment), with a model spread (5-95\% range) in both cases of $\pm 0.3^{\circ} \mathrm{C}$ (ref. ${ }^{24}$ ). However, since most of the models included in this ensemble did not include the effect of permafrost carbon feedbacks, we shifted the mean ZEC estimate from ZECMIP upward, to be centered on $0{ }^{\circ} \mathrm{C}$, based on the difference in the 50 -year ZEC in the UVic ESCM (ref. ${ }^{66}$ ) between model versions with and without permafrost carbon feedbacks. This resulted in a ZEC distribution of $0 \pm 0.3{ }^{\circ} \mathrm{C}$ as the mean and $5-95 \%$ uncertainty range for $\Delta T_{Z E C}$ (see Supplementary Fig. S4).
Finally, we derived distributions of the TCRE and RCBs, including their respective medians and uncertainty ranges, by sampling the distributions of input parameters in Eqs. (1) and (3). These inputs are based on either empirical distributions or normal distributions representing the spread of uncertainty in each of the parameters. Here, we assume that the uncertainty ranges in the input distributions are uncorrelated. While these quantities are obviously related in a coupled system, (e.g. warming being a function of $f_{n c}$ and $E$ ), we are not concerned with how one quantity is correlated with, or changes as a result of changes in other quantities, because our main interest is the uncertainty associated with the value of a particular quantity. As these uncertainty estimates come from different observations or models, and are based on uncertainties around today's values, they can be assumed to have uncorrelated uncertainty ranges, and thus, a direct sampling method is justified. We do note, however, that the tails of the distributions in figures. 1 and 2 are more sensitive to the assumptions of our framework; we show 5-95\% ranges to allow comparison with other studies, though we acknowledge that this range is less robust than the median and 33-67\% ranges that we have reported for the RCB distribution.

\section{Data availability}

SR1.5 scenarios are available at: https://data.ene.iiasa.ac.at/iamc-1.5c-explorer/. Anthropogenic warming estimate is available at: http://www.globalwarmingindex.org/.

\section{Code availability}

The FaIR model emulator is available at: https://github.com/OMS-NetZero/FAIR and can also be installed from: https://pypi.org/project/FaIR/. Codes for producing the figures are available from: https://github.com/ktokarska/remaining_carbon_budgets.

Received: 14 September 2020; Accepted: 16 November 2020; Published online: 18 January 2021

\section{References}

1. Rogelj, J. et al. Mitigation pathways compatible with $1.5^{\circ} \mathrm{C}$ in the context of sustainable development. In: Global warming of $1.5^{\circ} \mathrm{C}$. An IPCC special report on the impacts of global warming of $1.5^{\circ} \mathrm{C}$ above pre-industrial levels and related global greenhouse gas emission pathways, in the context of strengthening the global response to the threat of climate change, sustainable development, and efforts to eradicate poverty (eds Masson-Delmotte, V. et al.) In Press (2018).

2. Rogelj, J., Forster, P. M., Kriegler, E., Smith, C. J. \& Séférian, R. Estimating and tracking the remaining carbon budget for stringent climate targets. Nature 571, 335-342 (2019).

3. UNFCC. Adoption of the Paris Agreement. FCCC/CP/2015/L.9/Rev.1. 1-32 (UNFCCC, Paris, France, 2015).

4. Tokarska, K. B. et al. Recommended temperature metrics for carbon budget estimates, model evaluation and climate policy. Nat. Geosci. 12, 964-971 (2019).

5. IPCC. Climate Change 2014: Synthesis Report. Contribution of Working Groups I, II and III to the Fifth Assessment Report of the Intergovernmental Panel on Climate Change. (Core Writing Team, R. K. Pachauri and L. A. Meyer). 1-151 (IPCC, Geneva, Switzerland, 2014).

6. Friedlingstein, P. et al. Persistent growth of $\mathrm{CO}_{2}$ emissions and implications for reaching climate targets. Nature Geosci. 7, 709-715 (2014).

7. Matthews, H. D. et al. Estimating carbon budgets for ambitious climate targets. Curr Clim Change Rep. 3, 69-77 (2017).

8. Gasser, T. Path-dependent reductions in $\mathrm{CO}_{2}$ emission budgets caused by permafrost carbon release. Nat. Geosci. 11, 830-835 (2018).

9. Goodwin, P. et al. Pathways to $1.5^{\circ} \mathrm{C}$ and $2{ }^{\circ} \mathrm{C}$ warming based on observational and geological constraints. Nat. Geosci. 11, 102 (2018).

10. Mengis, N., Partanen, A.-I., Jalbert, J. \& Matthews, H. D. $1.5^{\circ} \mathrm{C}$ carbon budget dependent on carbon cycle uncertainty and future non- $\mathrm{CO}_{2}$ forcing. Sci. Rep. 8, 5831 (2018).

11. Millar, R. J. et al. Emission budgets and pathways consistent with limiting warming to $1.5^{\circ} \mathrm{C}$. Nat. Geosci. 10, 741-747 (2017).

12. Tokarska, K. B. \& Gillett, N. P. Cumulative carbon emissions budgets consistent with $1.5^{\circ} \mathrm{C}$ global warming. Nat. Clim. Change 8, 296-299 (2018).

13. Rogelj, J. et al. Scenarios towards limiting global mean temperature increase below $1.5^{\circ} \mathrm{C}$. Nat. Clim. Change 8, 325-332 (2018).

14. Matthews, H. D. et al. Opportunities and challenges in using carbon budgets as a guide for climate policy. Nat. Geosci. 13, 769-779 (2020).

15. Matthews, H. D., Gillett, N. P., Stott, P. A. \& Zickfeld, K. The proportionality of global warming to cumulative carbon emissions. Nature 459, 829-832 (2009).

16. Gillett, N. P., Arora, V. K., Matthews, D. \& Allen, M. R. Constraining the ratio of global warming to cumulative $\mathrm{CO}_{2}$ emissions using CMIP5 simulations. J. Clim. 26, 6844-6858 (2013).

17. Collins, et al. Long-term Climate Change: Projections, Commitments and Irreversibility. In: Climate Change 2013: The Physical Science Basis. 
Contribution of Working Group I to the Fifth Assessment Report of the Intergovernmental Panel on Climate Change (eds Stocker, T. F. et al.) (Cambridge University Press, Cambridge, United Kingdom and New York, NY, USA, 2013).

18. Smith, C. J. et al. FAIR v1.3: a simple emissions-based impulse response and carbon cycle model. Geosci. Model Dev. 11, 2273-2297 (2018).

19. Millar, R. J., Nicholls, Z. R., Friedlingstein, P. \& Allen, M. R. A modified impulse-response representation of the global near-surface air temperature and atmospheric concentration response to carbon dioxide emissions. Atmos. Chem. Phys. 17, 7213-7228 (2017).

20. Meinshausen, M., Raper, S. C. B. \& Wigley, T. M. L. Emulating coupled atmosphere-ocean and carbon cycle models with a simpler model, MAGICC6 - Part 1: Model description and calibration. Atmos. Chem. Phys. 11, 1417-1456 (2011).

21. Krasting, J. P., Dunne, J. P., Shevliakova, E. \& Stouffer, R. J. Trajectory sensitivity of the transient climate response to cumulative carbon emissions. Geophys. Res. Lett. 41, 2520-2527 (2014).

22. Haustein, K. et al. A real-time Global Warming Index. Sci. Rep. 7, 15417 (2017).

23. Friedlingstein, P. et al. Global carbon budget 2019. Earth Syst. Sci. Data 11, 1783-1838 (2019).

24. MacDougall et al. Is there warming in the pipeline? A multi-model analysis of the Zero Emissions Commitment from $\mathrm{CO}_{2}$. Biogeosci. 17, 2987-3016 (2020).

25. Huppmann, D., Rogelj, J., Kriegler, E., Krey, V. \& Riahi, K. A new scenario resource for integrated $1.5^{\circ} \mathrm{C}$ research. Nat. Clim Change 8, 1027-1030 (2018).

26. Huppmann, D. et al. IAMC $1.5^{\circ} \mathrm{C}$ scenario explorer and data hosted by IIASA. International Institute for Applied Systems Analysis \& Integrated Assessment Modeling Consortium. https://doi.org/10.22022/SR15/08-2018.15429 (2018).

27. Rogelj, J., Schleussner, C.-F. \& Hare, W. Getting it right matters: temperature goal interpretations in geoscience research. Geophys. Res. Lett. 44, 10, 662-10, 665 (2017).

28. Schleussner, C.-F. et al. Science and policy characteristics of the Paris Agreement temperature goal. Nat. Clim. Change 6, 827-835 (2016).

29. Stocker, T. F. et al. Technical Summary. In: Climate Change 2013: The Physical Science Basis. Contribution of Working Group I to the Fifth Assessment Report of the Intergovernmental Panel on Climate Change. (eds Stocker, T. F. et al.) 33-115 (Cambridge University Press, Cambridge, United Kingdom and New York, NY, USA, 2013).

30. Meinshausen, M. et al. Greenhouse-gas emission targets for limiting global warming to $2{ }^{\circ} \mathrm{C}$. Nature 458, 1158-1162 (2009).

31. Allen, M. R. et al. Warming caused by cumulative carbon emissions towards the trillionth tonne. Nature 458, 1163-1166 (2009).

32. Zickfeld, K., Arora, V. K. \& Gillett, N. P. Is the climate response to $\mathrm{CO}_{2}$ emissions path dependent? Geophys. Res. Lett. 39, (2012).

33. Rogelj, J., Meinshausen, M. \& Knutti, R. Global warming under old and new scenarios using IPCC climate sensitivity range estimates. Nat. Clim. Change 2, 248-253 (2012).

34. Matthews, H. D., Solomon, S. \& Pierrehumbert, R. Cumulative carbon as a policy framework for achieving climate stabilization. Proc. R. Soc. A 370, 4365-4379 (2012).

35. Zickfeld, $\mathrm{K}$. et al. Long-term climate change commitment and reversibility: an EMIC intercomparison. J. Clim. 26, 5782-5809 (2013).

36. Friedlingstein, P. et al. Uncertainties in CMIP5 climate projections due to carbon cycle feedbacks. J. Clim. 27, 511-526 (2013).

37. Tachiiri, K., Hajima, T. \& Kawamiya, M. Increase of uncertainty in transient climate response to cumulative carbon emissions after stabilization of atmospheric $\mathrm{CO}_{2}$ concentration. Environ. Res. Lett. 10, 125018 (2015).

38. Goodwin, P., Williams, R. G. \& Ridgwell, A. Sensitivity of climate to cumulative carbon emissions due to compensation of ocean heat and carbon uptake. Nat. Geosci. 8, 29-34 (2015).

39. MacDougall, A. H. The oceanic origin of path-independent carbon budgets. Sci. Rep. 7, 10373 (2017)

40. Millar, R. J. \& Friedlingstein, P. The utility of the historical record for assessing the transient climate response to cumulative emissions. Phil. Trans. R. Soc. A 376, 20160449 (2018).

41. Katavouta, A., Williams, R. G., Goodwin, P. \& Roussenov, V. Reconciling atmospheric and oceanic views of the transient climate response to emissions. Geophys. Res. Lett. 45, 6205-6214 (2018)

42. Spafford, L. \& MacDougall, A. H. Quantifying the probability distribution function of the transient climate response to cumulative $\mathrm{CO}_{2}$ emissions. Environ. Res. Lett. 15, 034044 (2020).

43. Rogelj, J. et al. Mitigation choices impact carbon budget size compatible with low temperature goals. Environ. Res. Lett. 10, 075003 (2015).

44. Leduc, M., Matthews, H. D. \& de Elía, R. Regional estimates of the transient climate response to cumulative $\mathrm{CO}_{2}$ emissions. Nat. Clim. Change 6, 474 (2016).

45. Tokarska, K. B., Gillett, N. P., Weaver, A. J., Arora, V. K. \& Eby, M. The climate response to five trillion tonnes of carbon. Nat. Clim. Change $\mathbf{6}$, 851-855 (2016).
46. Steffen, W. et al. Trajectories of the earth system in the anthropocene. PNAS $115,8252-8259$ (2018).

47. Armour, K. C., Bitz, C. M. \& Roe, G. H. Time-varying climate sensitivity from regional feedbacks. J. Clim. 26, 4518-4534 (2013).

48. Rugenstein, M. A. A., Sedláček, J. \& Knutti, R. Nonlinearities in patterns of long-term ocean warming. Geophys. Res. Lett. 43, 3380-3388 (2016).

49. Andrews, T. et al. Accounting for changing temperature patterns increases historical estimates of climate sensitivity. Geophys. Res. Lett. 45, 8490-8499 (2018).

50. Richardson, T. B. et al. Efficacy of climate forcings in PDRMIP models. $J$ Geophys Res. 124, 824-12 (2019).

51. Rogelj, J. et al. A new scenario logic for the Paris Agreement long-term temperature goal. Nature 573, 357-363 (2019).

52. Lelieveld, J., Evans, J. S., Fnais, M., Giannadaki, D. \& Pozzer, A. The contribution of outdoor air pollution sources to premature mortality on a global scale. Nature 525, 367-371 (2015).

53. Shindell, D. \& Smith, C. J. Climate and air-quality benefits of a realistic phaseout of fossil fuels. Nature 573, 408-411 (2019).

54. Jones, C. D. et al. The Zero Emissions Commitment Model Intercomparison Project (ZECMIP) contribution to C4MIP: quantifying committed climate changes following zero carbon emissions. Geosci. Model Dev. 12, 4375-4385 (2019).

55. Cowtan, K. \& Way, R. G. Coverage bias in the HadCRUT4 temperature series and its impact on recent temperature trends. Q J Roy Meteorol Soc 140, 1935-1944 (2014)

56. Lenssen, N. J. L. et al. Improvements in the GISTEMP Uncertainty Model. J. Geophys. Res. 124, 6307-6326 (2019).

57. Rohde, R. et al. A new estimate of the average earth surface land temperature spanning 1753 to 2011. Geoinfor. Geostat. 1, 1 (2013)

58. Vose, R. S. et al. NOAA's merged land-ocean surface temperature analysis. Bull. Am. Meteorol. Soc. 93, 1677-1685 (2012).

59. Morice, C. P., Kennedy, J. J., Rayner, N. A. \& Jones, P. D. Quantifying uncertainties in global and regional temperature change using an ensemble of observational estimates: the HadCRUT4 data set. J. Geophys. Res. 117, 8101 (2012).

60. Kennedy, J., Rayner, N. A., Atkinson, C. P. \& Killick, R. E. An ensemble data set of sea surface temperature change from 1850: the Met Office Hadley Centre HadSST.4.0.0.0 Data Set. J. Geophys. Res. 124, 7719-7763 (2019).

61. Tokarska, K. B. et al. Uncertainty in carbon budget estimates due to internal climate variability. Environ. Res. Lett. 15, 104064 (2020).

62. Bellouin, N. et al. Bounding global aerosol radiative forcing of climate change. Rev. Geophys. 58, e2019RG000660 (2020).

63. Smith, C. J. et al. Understanding rapid adjustments to diverse forcing agents. Geophys. Res. Lett. 45, 12, 023-12, 031 (2018).

64. Etminan, M., Myhre, G., Highwood, E. J. \& Shine, K. P. Radiative forcing of carbon dioxide, methane, and nitrous oxide: a significant revision of the methane radiative forcing. Geophys. Res. Lett. 43, 12, 614-12, 623 (2016).

65. Nicholls, Z. R. J. et al. Reduced Complexity Model Intercomparison Project Phase 1: introduction and evaluation of global-mean temperature response. Geosci. Model Dev. 13, 5175-5190 (2020).

66. Mengis, N. et al. Evaluation of the University of Victoria Earth System Climate Model version 2.10 (UVic ESCM 2.10). Geosci. Model Dev. 13, 4183-4204 (2020).

\section{Acknowledgements}

We are thankful to Martin B. Stolpe for helpful discussion on temperature datasets. We are thankful for the discussions at the International Workshop on the Remaining Carbon Budget, held in January 2019 with the support of the Global Carbon Project, the CRESCENDO project, Stanford University, the University of Melbourne and Simon Fraser University. KBT, PMF, JR, CJS and RK acknowledge funding from the European Union's Horizon 2020 research and innovation programme under grant agreement no. 820829 (CONSTRAIN project). HDM and AHMD acknowledge funding from the Natural Sciences and Engineering Research Council of Canada Discovery Grant programme.

\section{Author contributions}

HDM developed the framework. KBT, HDM and JR initiated the study and framed the paper. KBT performed the analysis with assistance from SS, HDM and JR. KBT plotted the figures in the main paper. KBT and HDM wrote the paper with contributions from remaining co-authors. CJS provided the radiative forcing data with input from HDM, $\mathrm{KBT}$ and JR. KH provided the anthropogenic warming estimates, AHMD provided the zero-emission commitment estimates. NM, PF and RK assisted with framing and writing this paper. All authors contributed to manuscript editing and revisions.

\section{Competing interests}

The authors declare no competing interests. 


\section{Additional information}

Supplementary information is available for this paper at https://doi.org/10.1038/s43247020-00064-9.

Correspondence and requests for materials should be addressed to H.D.M. or K.B.T.

Peer review information Primary handling editor: Heike Langenberg

Reprints and permission information is available at http://www.nature.com/reprints

Publisher's note Springer Nature remains neutral with regard to jurisdictional claims in published maps and institutional affiliations. (c) (1) Open Access This article is licensed under a Creative Commons Attribution 4.0 International License, which permits use, sharing, adaptation, distribution and reproduction in any medium or format, as long as you give appropriate credit to the original author(s) and the source, provide a link to the Creative Commons license, and indicate if changes were made. The images or other third party material in this article are included in the article's Creative Commons license, unless indicated otherwise in a credit line to the material. If material is not included in the article's Creative Commons license and your intended use is not permitted by statutory regulation or exceeds the permitted use, you will need to obtain permission directly from the copyright holder. To view a copy of this license, visit http://creativecommons.org/licenses/by/4.0/.

(c) The Author(s) 2021 